\section{A) Check for updates}

Cite this: Analyst, 2017, 142, 4299

\title{
Highly active 3-dimensional cobalt oxide nanostructures on the flexible carbon substrates for enzymeless glucose sensing $\dagger$
}

\author{
Palanisamy Kannan, (iD ${ }^{a, b}$ Thandavarayan Maiyalagan, (iD c Enrico Marsili, (DD *b \\ Srabanti Ghosh, (D) ${ }^{d}$ Longhua Guo, (D) e Youju Huang, ${ }^{f}$ Jahangir Ahmed Rather, ${ }^{g}$

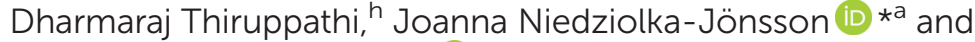 \\ Martin Jönsson-Niedziolka (D) *a
}

\begin{abstract}
The demand for electrochemical sensors with high sensitivity and reliability, fast response, and excellent selectivity has stimulated intensive research on developing highly active nanomaterials. In this work, freestanding $3 \mathrm{D} / \mathrm{CO}_{3} \mathrm{O}_{4}$ thorn-like and wire-like (nanowires) nanostructures are directly grown on a flexible carbon fiber paper (CFP) substrate by a single-step hydrothermal process without using surfactants or templates. The $3 \mathrm{D} / \mathrm{CO}_{3} \mathrm{O}_{4}$ thorn-like nanostructures show higher electrochemical activity than wire-like because of their high conductivity, large specific surface areas, and mesopores on their surface. The characterization of $3 \mathrm{D} / \mathrm{CO}_{3} \mathrm{O}_{4}$ nanostructures is performed by using high resolution transmission electron microscopy (HRTEM), field emission scanning electron microscopy (FESEM), X-ray photoelectron spectroscopy (XPS), X-ray diffraction analysis (XRD), and electrochemical methods. The $3 \mathrm{D} / \mathrm{CO}_{3} \mathrm{O}_{4}$ thorn-like nanostructures displayed non-enzymatic higher catalytic activity towards the electrochemical detection of glucose, compared to the $3 \mathrm{D} / \mathrm{CO}_{3} \mathrm{O}_{4}$ wire-like morphology. The $3 \mathrm{D} / \mathrm{CO}_{3} \mathrm{O}_{4}$ thorn-like nanostructures show a wide linear range response of glucose concentration ranging from 1 to $1000 \mu \mathrm{M}$ with a detection limit of $0.046 \mu \mathrm{M}(\mathrm{S} / \mathrm{N}=3)$. The $3 \mathrm{D} / \mathrm{CO}_{3} \mathrm{O}_{4}$ thorn-like nanostructure-modified CFP electrode selectively detects glucose in the presence of 100 -fold excess of interfering compounds. The $3 \mathrm{D} / \mathrm{CO}_{3} \mathrm{O}_{4}$ thorn-like nanostructure-modified CFP electrode is tested with human blood serum samples and validated with commercial glucose sensors. The newly developed sensor material shows potential for glucose monitoring in clinical and food samples.
\end{abstract}

Received 29th June 2017, Accepted 11th September 2017

DOI: 10.1039/c7an01084b

rsc.li/analyst

\footnotetext{
${ }^{a}$ Institute of Physical Chemistry, Polish Academy of Sciences, 44/52 ul. Kasprzaka, 01-224 Warsaw,Poland.E-mail: joaniek@ichf.edu.pl, martinj@ichf.edu.pl; Fax: $+48223433333 ;$ Tel: +48223433130

${ }^{b}$ Singapore Centre for Environmental Life Sciences Engineering (SCELSE), Nanyang Technological University, 60 Nanyang Drive, SBS-01N-27, Singapore. E-mail: emarsili@ntu.edu.sg; Fax: +65-6515-6751; Tel: +65-6592-7895

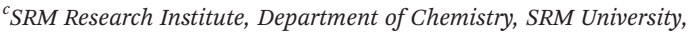
Kattankulathur - 603203, Chennai, India

${ }^{d}$ Department of Chemical, Biological and Macromolecular Sciences, S. N. Bose National Centre for Basic Sciences, Block-JD, Sector-III, Salt Lake, Kolkata-700098, India

${ }^{e}$ Institute of Nanomedicine and Nanobiosensing, Key Laboratory of Analysis and Detection Technology for Food Safety (Ministry of Education), College of Chemistry, Fuzhou University, Fuzhou, 350116, China

${ }^{f}$ Division of Polymer and Composite Materials, Ningbo Institute of Materials Technology and Engineering, Chinese Academy of Sciences, Ningbo 315201, P. R. China

${ }^{g}$ Department of Chemistry, Sultan Qaboos University, Box 36, Al-Khod 123, Oman

${ }^{h}$ Department of Chemistry, Vivekananda College, Thiruvedakam West,

Madurai 625234, India

$\dagger$ Electronic supplementary information (ESI) available. See DOI: 10.1039/ c7an01084b
}

\section{Introduction}

Rapid, sensitive and selective glucose sensing is in high demand due to the increasing need for monitoring diabetes patients. ${ }^{1-3}$ In fact, insulin deficiency is a leading cause of death and permanent disability. ${ }^{1,4}$ Diabetic patients must test their blood glucose levels on daily basis and often multiple times per day, making glucose the most commonly tested analyte. Hence, the development of high performance glucose sensors is of paramount importance. Currently available sensors for glucose are based on fluorescence, colorimetric, chemiluminescence, and chromatography methods. ${ }^{5}$ Commercial glucose biosensors based on immobilized enzymes show high sensitivity and selectivity. However, immobilized enzymes are sensitive to denaturation by environmental factors, can be damaged by proteases, and their purification is costly and time-consuming. ${ }^{6,7}$ Consequently, much effort has been devoted to developing non-enzymatic glucose sensors. 
Recent studies evidenced that transition metal oxides such as manganese oxide, nickel oxide, zinc oxide, and copper oxide have specific catalytic activity. ${ }^{8-16}$ Cobalt oxide $^{17,18}$ is particularly interesting because it has three well-known polymorphs: the cobaltous oxide (CoO), the cobaltic oxide $\left(\mathrm{Co}_{2} \mathrm{O}_{3}\right)$ and the cobaltosic oxide $\left(\mathrm{Co}_{3} \mathrm{O}_{4}\right) \cdot{ }^{19}$ Compared to the two other polymorphs, $\mathrm{Co}_{3} \mathrm{O}_{4}$ might find application in energy storage, ${ }^{20-23}$ heterogeneous catalysts $^{24}$ electrochromic devices, ${ }^{25}$ oxygen reduction reactions ${ }^{26}$ and electrochemical sensors. ${ }^{27-33}$ Recently, 1-D morphologies of $\mathrm{Co}_{3} \mathrm{O}_{4}$ such as nanotubes, nanowires, nanobelts, flower-like, and needle-like structures have been synthesized by using vapor phase transport methods, ${ }^{34}$ electrospinning, ${ }^{28}$ porous alumina, ${ }^{35}$ ammonia-evaporation induction, ${ }^{36,37}$ template-assisted processes, ${ }^{38}$ and hydrothermal synthesis methods. ${ }^{39}$ Introducing supports into the $\mathrm{Co}_{3} \mathrm{O}_{4}$ nanomaterial is crucial to fabricate high performance nanostructures for technological applications. ${ }^{39-41}$ For instance, Chen et al. synthesized the $\mathrm{Co}_{3} \mathrm{O}_{4}$ nanotubes via the anodic aluminum oxide (AAO) template route and applied them in lithium batteries. ${ }^{35}$ Wang et al. prepared $\mathrm{Ni}$ foam supported- $\mathrm{Co}_{3} \mathrm{O}_{4}$ nanowire arrays for the electroreduction of hydrogen peroxide. ${ }^{42}$ Chen and coworkers prepared flower-like $\mathrm{Co}_{3} \mathrm{O}_{4}$ supported on $3 \mathrm{D}$ carbon foam $\left(\mathrm{Co}_{3} \mathrm{O}_{4} @ \mathrm{CF}\right)$ by the hydrothermal treatment of the 3D carbon material and used for ethanol sensing. ${ }^{43}$ Dong and coworkers synthesized a $3 \mathrm{D}$ graphene $/ \mathrm{Co}_{3} \mathrm{O}_{4}$ nanowire composite, which serves as a self-supporting monolithic electrode for super-capacitors and the enzyme-free electrochemical detection of glucose. ${ }^{27}$ Despite these achievements, current synthetic methods suffer from either the removal of templates or the use of structure directing agents. A scalable synthesis of $\mathrm{Co}_{3} \mathrm{O}_{4}$ nanostructures remains a challenge; thus, there is the need for a low cost, simple, and scalable synthesis route for the preparation of $\mathrm{Co}_{3} \mathrm{O}_{4}$.

In this work, three-dimensional $(3 \mathrm{D}) \mathrm{Co}_{3} \mathrm{O}_{4}$ thorn-like and nanowire structures were synthesized on a flexible carbon fiber paper (CFP) substrate via a template-free growth method. The CFP served as both the current collector and the support for $\mathrm{Co}_{3} \mathrm{O}_{4}$ nanostructures. CFP has been utilized for the fabrication of large load-bearing composites due to its tensile strength, stiffness, and low density. ${ }^{44,45}$ CFP is a promising current collector and a backbone for conformal coating of transition metal oxides for sensors without using any insulating binders. ${ }^{46}$ Individual carbon fibers in the CFP are well-connected and the conductive network and pore channels create an efficient electron percolation path as well as enable electrolyte access to the electrochemically active nanomaterials without limiting charge transport. ${ }^{46}$ Thus, we have grown $3 \mathrm{D} /$ $\mathrm{Co}_{3} \mathrm{O}_{4}$ thorn-like and nanowire morphologies on the CFP surface by changing the ratio of $\mathrm{CoCl}_{2}$ and urea. Next, we have studied the non-enzymatic detection of glucose using the assynthesized $3 \mathrm{D} / \mathrm{Co}_{3} \mathrm{O}_{4}$ thorn-like and nanowire morphologies on the CFP surface. The $3 \mathrm{D} / \mathrm{Co}_{3} \mathrm{O}_{4}$ thorn-like nanostructures offer a large active surface area, not only by increasing the electrolyte transport rate, but also allowing a close contact between the electrolyte and active surfaces through pores and channels (biomolecules). The 3D self-supported networks with interlaced bridging frameworks maintain the stability of $\mathrm{Co}_{3} \mathrm{O}_{4}$ thorn-like nanostructures after repeated measurements, thus ensuring repeatable glucose detection.

\section{Experimental section}

\section{Materials}

$\mathrm{CoCl}_{2} \cdot 6 \mathrm{H}_{2} \mathrm{O}$ and nitric acid $\left(\mathrm{HNO}_{3}\right)$ were obtained from SigmaAldrich. Urea (>99\%) was purchased from Merck. All other chemicals were of analytical grade, and used as received. Carbon fiber paper was purchased from Protech Composites Inc., WA, USA. All the solutions were prepared with Millipore water $(18 \mathrm{M} \Omega \mathrm{cm})$ obtained from an Elix Millipore system. The human blood serum samples were collected from Muthu clinic and X-rays, Dindigul district, India. Argon (99.99\%) was supplied by Multax Company, Poland.

\section{Preparation of $3 \mathrm{D}-\mathrm{Co}_{3} \mathrm{O}_{4}$ thorn-like and nanowires on the flex- ible CFP substrate}

The CFP substrates were pre-treated based on our recent report. ${ }^{47}$ To obtain $\mathrm{Co}_{3} \mathrm{O}_{4}$ thorn-like nanostructures, $\mathrm{CoCl}_{2} \cdot 6 \mathrm{H}_{2} \mathrm{O}(1 \mathrm{mmol})$ and urea $(2.0 \mathrm{mmol})$ were added to $20 \mathrm{~mL}$ of water and continuously stirred for $10 \mathrm{~min}$. The mixture was then transferred into a Teflon-lined stainless-steel autoclave of $50 \mathrm{~mL}$ capacity, and pretreated CFP was inserted into the reaction vessel. The nanostructures on the CFP substrate were formed by autoclaving at $120{ }^{\circ} \mathrm{C}$ for $12 \mathrm{~h}$ and cooling at room temperature, thus resulting in the deposition of nanostructures on the CFP substrate. The nano-modified CFP substrate was further washed with deionized water and dried at $60{ }^{\circ} \mathrm{C}$ before use. The $\mathrm{Co}_{3} \mathrm{O}_{4}$ nanowires were obtained through a similar procedure, with $\mathrm{CoCl}_{2} \cdot 6 \mathrm{H}_{2} \mathrm{O}(2 \mathrm{mmol})$ and urea $(1.0 \mathrm{mmol})$ as precursors. The $\mathrm{Co}_{3} \mathrm{O}_{4}$ coated CFP substrate was used as a working electrode for the enzymeless glucose sensing experiments.

\section{Instrumentation}

The morphology of the $\mathrm{Co}_{3} \mathrm{O}_{4}$ was examined by field-emission scanning electron microscopy (FESEM, JEOL-JSM-6700F). High-resolution transmission electron microscopy (HRTEM) was carried out using a JEOL JEM 3010 instrument with an accelerating voltage of $200 \mathrm{kV}$. The samples were placed on a carbon-coated copper grid for morphology and size analysis. The crystallographic information was obtained by the powder X-ray diffraction technique (XRD, Shimadzu XRD-6000, Ni filtered $\operatorname{CuK} \alpha(\lambda=1.54 \AA)$ radiation operating at $30 \mathrm{kV} / 40 \mathrm{~mA})$. $\mathrm{X}$-ray photoelectron spectroscopy (XPS) analysis was performed on a VG ESCALAB MK II spectrometer with an Mg-K $\alpha$ (1253.6 eV) achromatic X-ray source. The specific surface area of the nanostructures was determined using the BET method (the Brunauer-Emmett-Teller isotherm). The chemical composition of the $\mathrm{Co}_{3} \mathrm{O}_{4}$ samples was confirmed by using a Varian 710-ES Inductively Coupled Plasma (ICP)-Optical Emission Spectrometer (OES). Electrochemical measurements were per- 
formed with three electrode cells with CFP (exposed geometric area $\left.=0.16 \mathrm{~cm}^{2}\right)$, a Pt wire, and $\mathrm{Ag} \mid \mathrm{AgCl}(3 \mathrm{M} \mathrm{KCl})$ as working, auxiliary and reference electrodes, respectively. Cyclic voltammetry and chronoamperometry were performed using an Autolab PGSTAT30 (Metrohm Autolab) electrochemical analyzer. All electrochemical experiments were carried out under an argon atmosphere. Electrochemical impedance spectroscopy (EIS) measurements were conducted for the $\mathrm{Co}_{3} \mathrm{O}_{4}$ nanostructure-modified CFP electrodes in the frequency range of $200 \mathrm{kHz}$ to $0.01 \mathrm{~Hz}$. For real sample analysis, human blood serum samples were acquired from Muthu clinic and X-rays, Dindigul district, that adheres to the guidelines for good laboratory practices issued by the Indian Council of Medical Research (2008). The serum sample analysis and storage were done in agreement with human sample handling approval obtained from the Research Ethics Committee at the Department of Chemistry, SRM Research Institute.

\section{Results and discussion}

\section{Synthesis and characterization of $3 \mathrm{D} / \mathrm{Co}_{3} \mathrm{O}_{4}$ thorn-like and nanowires on the flexible CFP substrate}

We have recently synthesized $\mathrm{Ni}-\mathrm{Fe}$ nanostructures by changing the relative concentration of their precursors. ${ }^{47}$ In this study, we have investigated the morphology of $\mathrm{Co}_{3} \mathrm{O}_{4}$ nanostructures by changing the ratio between the precursor compounds, urea and $\mathrm{Co}_{3} \mathrm{O}_{4}$. The $\mathrm{Co}_{3} \mathrm{O}_{4}$ thorn-like nanostructure was synthesized by using $1 \mathrm{mmol}$ of $\mathrm{CoCl}_{2} \cdot 6 \mathrm{H}_{2} \mathrm{O}$ and $2.0 \mathrm{mmol}$ urea (1:2 ratio), and the corresponding FESEM images are shown in Fig. 1a-d. The $\mathrm{Co}_{3} \mathrm{O}_{4}$ thorn-like nanostructures formed on the flexible CFP surface are networked, upright, outward, and densely packed, which is favorable for highly
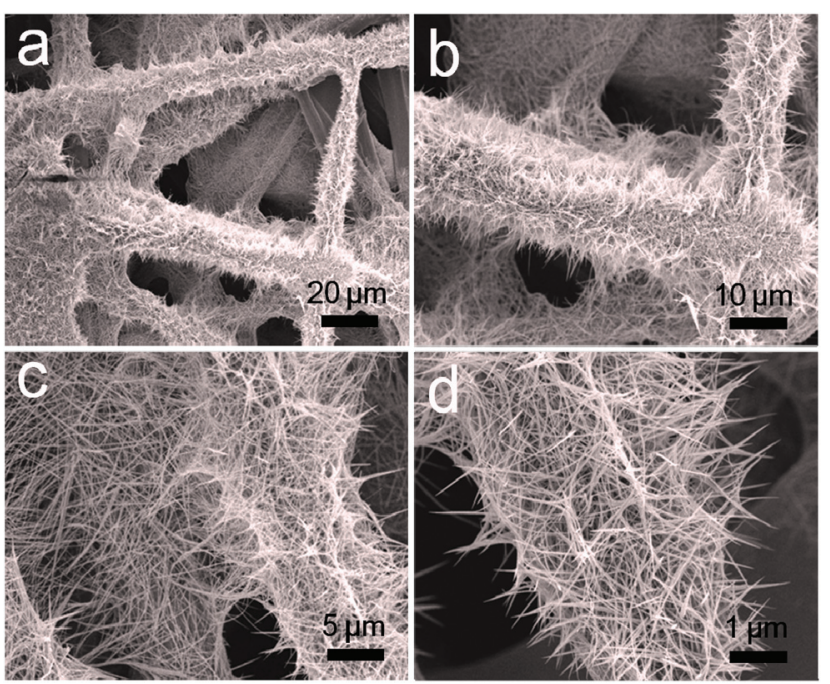

Fig. 1 Low $(a, b)$ resolution FESEM images of $3 \mathrm{D} / \mathrm{Co}_{3} \mathrm{O}_{4}$ thorn-like nanostructures, and the corresponding enlarged FESEM images (c, d) showing the $3 \mathrm{D} / \mathrm{CO}_{3} \mathrm{O}_{4}$ thorn-like nanostructures networked with sharp needles. sensitive sensor applications. The thorn-like nanostructures are composed of several individual 3-4 $\mu \mathrm{m}$ long sharp needles (Fig. 1a and b). Each needle structured particle seemingly emanates from the surface of the CFP substrate. The enlarged FESEM images (Fig. 1c and d) show 3D thorn-like nanostructures on the CFP surface, which possess excellent mechanical strength and durability. ${ }^{47}$ Furthermore, these $\mathrm{Co}_{3} \mathrm{O}_{4}$ thorn-like nanostructures retain their morphology without any calcination/annealing process during the synthesis. ${ }^{47}$

The following growth mechanism of $3 \mathrm{D} / \mathrm{Co}_{3} \mathrm{O}_{4}$ thorn-like nanostructures is proposed; at first, small nanoparticle nuclei were formed and subsequently, and site-specific anisotropic growth occurred on the CFP by the asymmetrical self-assembly process (Scheme 1). Then, the particles keep on growing as thorn-like nanostructures (Fig. 1d) with many nano-needles sharing the same originating center through coarsening, also known as the Ostwald ripening process. Next, we used the $\mathrm{CoCl}_{2} \cdot 6 \mathrm{H}_{2} \mathrm{O}$ and urea ratio as $2: 1$ for preparation, which results in $3 \mathrm{D} / \mathrm{Co}_{3} \mathrm{O}_{4}$ nanowire morphology (Fig. 2a and b). The nanowires were grown densely on the CFP surface with a length of $\sim 12 \pm 2 \mu \mathrm{m}$ and a width of $110 \pm 5 \mathrm{~nm}$ (Fig. $2 \mathrm{~b}$ ).

The magnified FESEM images (Fig. $2 \mathrm{c}$ and $\mathrm{d}$ ) of the $3 \mathrm{D} /$ $\mathrm{Co}_{3} \mathrm{O}_{4}$ nanowires show a smooth surface. The following growth mechanism is proposed; seeds of Co nuclei (nanoparticles) were formed at the initial stage of the reaction, similar to the thorn-like nanostructures. Next, the nuclei gradually grew into small nanoparticles which may act as the seeds for the growth of larger nanoparticles. It is well known that the surface energy of larger particles is lower than that of the smaller ones; therefore, these small nanoparticles were grown into larger ones via an overgrowth or aggregation process. ${ }^{48-51}$ Afterwards, the adjacent large nanoparticles moved, met and then adhered to form a short chain-shaped structure (elongated nanorod structures). By prolonging the reaction time, the newly formed Co nanoparticle nuclei deposit onto the surface of the connected nanoparticles through the capillary phenomenon, leading to the formation of the nanowire morphology.

To understand the dimensionality of the $3 \mathrm{D} / \mathrm{Co}_{3} \mathrm{O}_{4}$ nanostructures, high-resolution transmission electron microscopy (HRTEM) was performed. Fig. 3a shows the HRTEM images of the $\mathrm{Co}_{3} \mathrm{O}_{4}$ thorn-like nanostructures. It is clearly seen that the $\mathrm{Co}_{3} \mathrm{O}_{4}$ thorn-like nanostructures are composed of several individual nanocrystals (Fig. 3b), with the size range of 30-40 nm, and mesoporous nature. Furthermore, nanometer $(2-5 \mathrm{~nm})$ pores are present in the individual needles of $3 \mathrm{D} / \mathrm{Co}_{3} \mathrm{O}_{4}$ thornlike nanostructures. On the other hand, a typical HRTEM image of a single nanowire (Fig. 3c) shows that the $3 \mathrm{D} / \mathrm{Co}_{3} \mathrm{O}_{4}$ nanowires are composed of numerous interconnected elongated nanorods (see Fig. 3d) with mesoporous nature (similar to thorn-like). The extended HRTEM image in Fig. 3e shows well-defined nanocrystalline lattice fringes of the $3 \mathrm{D} /$ $\mathrm{Co}_{3} \mathrm{O}_{4}$ thorn-like nanostructures. The measured gap between the two lattice fringes is $0.240 \mathrm{~nm}$, which corresponds to the (111) plane of the cubic crystalline nature of the $\mathrm{Co}_{3} \mathrm{O}_{4}$ thornlike nanostructures. Selected area electron diffraction (SAED) 


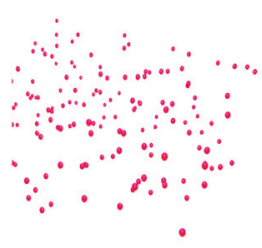

Co-nuclei

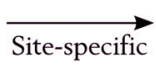

anisotropic

growth

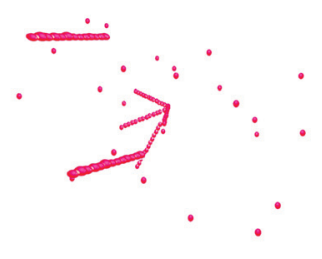

.

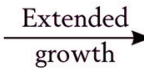

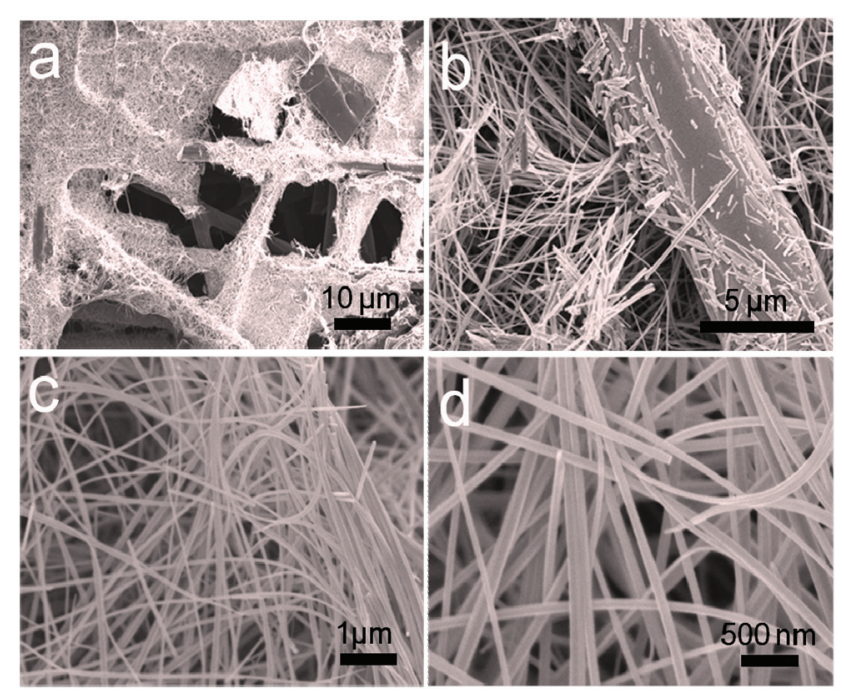

Fig. 2 Low $(a, b)$ resolution FESEM images of $3 \mathrm{D} / \mathrm{CO}_{3} \mathrm{O}_{4}$ nanowire morphology, and the corresponding enlarged FESEM images $(c, d)$ showing the network growth of $3 \mathrm{D} / \mathrm{CO}_{3} \mathrm{O}_{4}$ nanowires on the CFP surface.

was performed (Fig. 3f), and the diffraction rings indicate that the cubic crystalline $\mathrm{Co}_{3} \mathrm{O}_{4}$ assemble in the thorn-like nanostructures. The possible reactions involved in the synthesis of the $\mathrm{Co}_{3} \mathrm{O}_{4}$ nanostructures can be summarized as:

$$
\begin{gathered}
\mathrm{CoCl}_{2} \rightarrow \mathrm{Co}^{2+}+2 \mathrm{Cl}^{-} \\
\left(\mathrm{H}_{2} \mathrm{~N}\right)_{2}-\mathrm{CO}+\mathrm{H}_{2} \mathrm{O} \rightarrow 2 \mathrm{NH}_{3}+\mathrm{CO}_{2} \\
\mathrm{NH}_{3}+\mathrm{H}_{2} \mathrm{O} \rightarrow \mathrm{NH}^{4+}+\mathrm{OH}^{-}
\end{gathered}
$$

$$
\mathrm{Co}^{2+}+2 \mathrm{OH}^{-} \rightarrow \mathrm{Co}(\mathrm{OH})_{2}
$$

Cobalt hydroxide $\left(\mathrm{Co}(\mathrm{OH})_{2}\right)$ is thermodynamically unstable and it can change into the $\mathrm{Co}_{3} \mathrm{O}_{4}$ phase during the reaction. Eqn (3) plays an important role in the evolution of both thornlike and nanowire morphologies of $\mathrm{Co}_{3} \mathrm{O}_{4}$. The chemical compositions of the $3 \mathrm{D} / \mathrm{Co}_{3} \mathrm{O}_{4}$ nanostructure samples were confirmed by Inductively Coupled Plasma (ICP) - Optical Emission Spectroscopy (OES) analysis. The samples were dissolved in hot aqua regia, appropriately diluted and the results of three independent measurements were averaged. The mass loading of the $3 \mathrm{D} / \mathrm{Co}_{3} \mathrm{O}_{4}$ thorn-like nanostructures and the $3 \mathrm{D} /$ $\mathrm{Co}_{3} \mathrm{O}_{4}$ nanowire-modified CFP substrates was found to be 10.2 and $10.6 \mu \mathrm{g}$, respectively. The Brunner-Emmett-Teller (BET) active surface area of the $\mathrm{Co}_{3} \mathrm{O}_{4}$ thorn-like and nanowire catalysts was also measured. The nitrogen adsorption and desorption isotherms and pore size distribution of all porous nanostructures are shown in Fig. S1, ESI; $\dagger$ the hierarchical $\mathrm{Co}_{3} \mathrm{O}_{4}$ thorn-like nanostructures exhibited a higher BET surface area of $86.2 \mathrm{~m}^{2} \mathrm{~g}^{-1}$ (Fig. S1; curve a $\dagger$ ) than that of the nanowires of $67.5 \mathrm{~m}^{2} \mathrm{~g}^{-1}$ (Fig. S1; curve $\mathrm{b} \dagger$ ) with a pore size distribution of 5-9 $\mathrm{nm}$. To further characterize the electrochemical kinetics of the $3 \mathrm{D} / \mathrm{Co}_{3} \mathrm{O}_{4}$ nanostructure-modified CFP electrode, electrochemical impedance spectroscopy (EIS) ${ }^{52,53}$ measurements were performed from $200 \mathrm{kHz}$ to $0.01 \mathrm{~Hz}$, in which $Z^{\prime}$ and $Z^{\prime \prime}$ are the real and imaginary parts of the impedance, respectively. The measured EIS spectra were analyzed and an equivalent circuit for this cell system is shown in Fig. S2.† It is well known that the diameter of the semicircle in the EIS spectrum could represent the electron transfer resistance $\left(R_{\mathrm{ct}}\right)$, which controls the electron transfer kinetics of the redox reaction at the electrode interface. The Nyquist plots of the $3 \mathrm{D} / \mathrm{Co}_{3} \mathrm{O}_{4}$ thorn-like nanostructure CFP electrode (Fig. S2; curve $\mathrm{b}_{\dagger} \dagger$ ) 

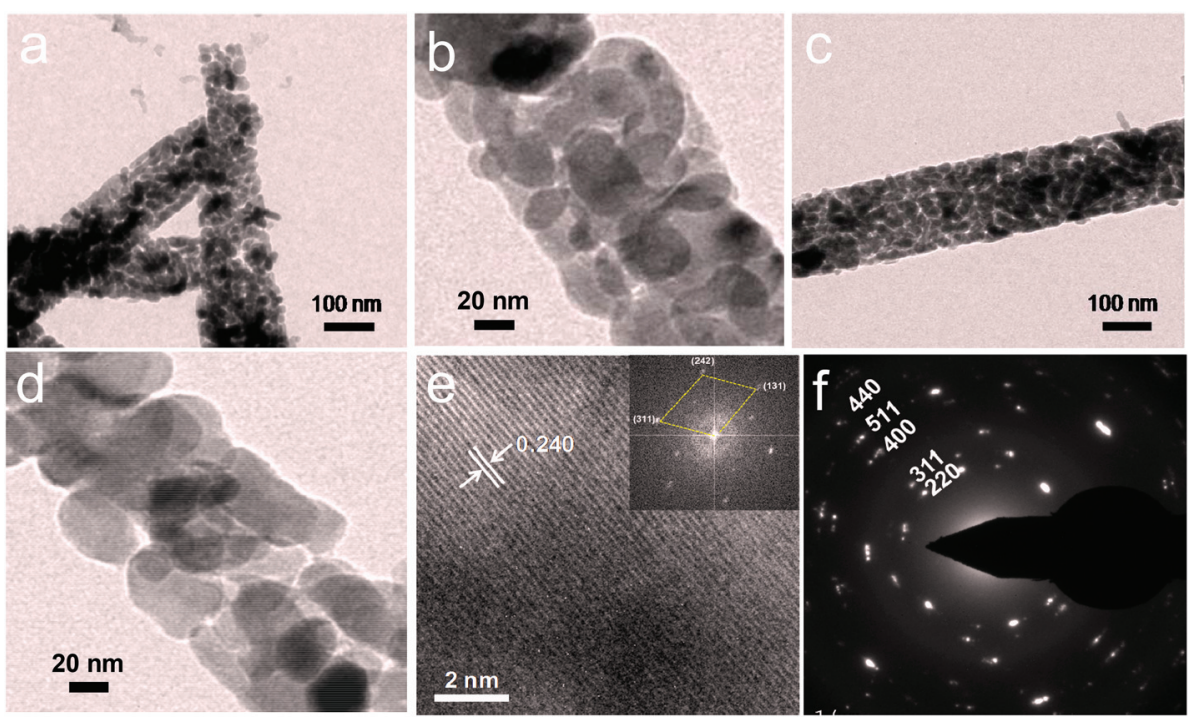

Fig. 3 HRTEM images of $\mathrm{CO}_{3} \mathrm{O}_{4}$ thorn-like (a), and the corresponding enlarged HRTEM image showing the porous nanostructure of the $\mathrm{CO}_{3} \mathrm{O}_{4}$ thorn-like morphology composed of several nanocrystals (b). HRTEM images of $\mathrm{Co}_{3} \mathrm{O}_{4}$ nanowires (c), and the corresponding enlarged HRTEM image showing the porous nanostructure of the $\mathrm{Co}_{3} \mathrm{O}_{4}$ nanowire morphology composed of several nanorods (d). Lattice fringes resolved the HRTEM image of a part of $\mathrm{CO}_{3} \mathrm{O}_{4}$ thorn-like nanostructures (e). The selected area electron diffraction (SAED) pattern showing the crystalline nature of the $\mathrm{CO}_{3} \mathrm{O}_{4}$ thorn-like nanostructures (f).

clearly show that the diameter of the semicircle was much smaller than that of the $3 \mathrm{D} / \mathrm{Co}_{3} \mathrm{O}_{4}$ nanowire CFP electrode (Fig. S2; curve c†), indicating that the thorn-like nanostructures enhanced the charge transfer process compared to nanowires. The values of charge-transfer resistance $R_{\text {ct }}$ of the $3 \mathrm{D} / \mathrm{Co}_{3} \mathrm{O}_{4}$ thorn-like nanostructures and nanowires were $253.5 \Omega$ and $358.0 \Omega$, respectively, which were significantly lower than that of the unmodified CFP electrode (853.4 $\Omega$; Fig. S2, curve a $\uparrow$ ). These results confirmed that the interconnected $3 \mathrm{D} / \mathrm{Co}_{3} \mathrm{O}_{4}$ thorn-like nanostructures not only preserved the high conductivity of the overall electrode, but also significantly enhanced the electrochemical activity of cobalt oxides during the catalysis processes.

An X-ray diffractogram of $3 \mathrm{D} / \mathrm{Co}_{3} \mathrm{O}_{4}$ nanowires (red line) and thorn-like (black line) nanostructures is shown in Fig. 4a. The lattice parameters of the as-synthesized $\mathrm{Co}_{3} \mathrm{O}_{4}$ nanostructures were the same as those given in the JCPDS No. 0431003, which also confirmed that the other cobalt oxides were not formed. It can be seen that all the diffraction peaks (111) phase $\left(2 \theta \approx 19.70^{\circ}\right),(220)$ phase $\left(2 \theta \approx 31.39^{\circ}\right)$, (311) phase $\left(2 \theta \approx 36.51^{\circ}\right),(222)$ phase $\left(2 \theta \approx 38.44^{\circ}\right)$, $(400)$ phase $\left(2 \theta \approx 44.89^{\circ}\right)$, (511) phase $\left(2 \theta \approx 59.87^{\circ}\right)$ and $(440)$ phase $\left(2 \theta \approx 65.77^{\circ}\right)$ can be indexed to a pure cubic phase of $\mathrm{Co}_{3} \mathrm{O}_{4}$ (space group $\mathrm{Fd} 3 \mathrm{~m}$ ) with a lattice constant of $8.084 \AA$ and there are no residual other impurity phase peaks found in the sample. ${ }^{54,55}$ Therefore, the formation of both nanocrystalline $3 \mathrm{D} / \mathrm{Co}_{3} \mathrm{O}_{4}$ nanowires and thorn-like nanostructures was in the high-pure phase.

Furthermore, no characteristic peaks corresponding to crystalline carbon are found in the XRD pattern, indicating that the carbon has amorphous nature in both $\mathrm{Co}_{3} \mathrm{O}_{4}$ nanostructures. Importantly, the ratio of the relative peak intensi-
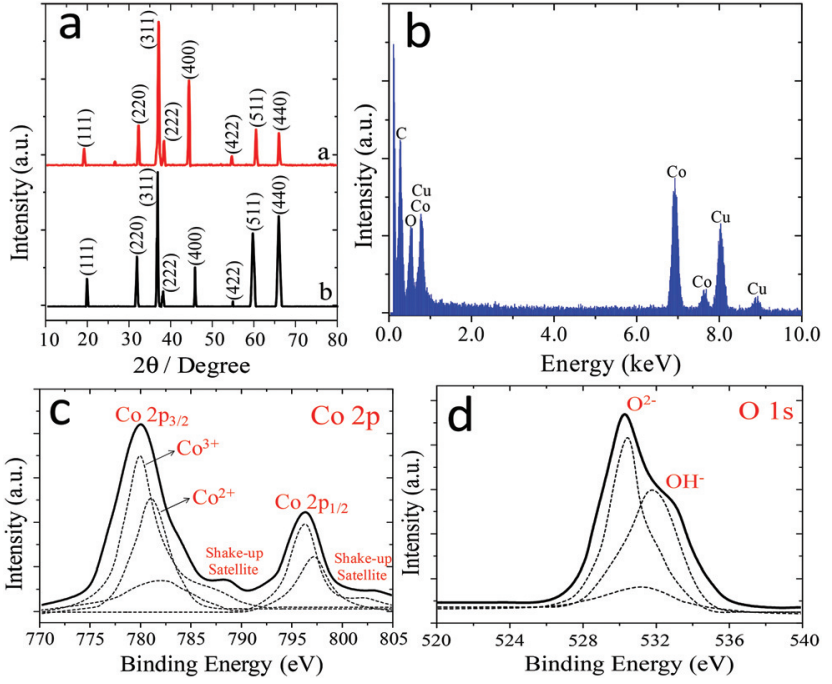

Fig. 4 (a) XRD patterns obtained for $\mathrm{CO}_{3} \mathrm{O}_{4}$ nanowires (curve $\mathrm{a}$; red line) and thorn-like (curve b; black line) nanostructures. The EDX (b) and XPS of $\mathrm{Co} 2 \mathrm{p}(\mathrm{c})$ and $\mathrm{O} 1 \mathrm{~s}(\mathrm{~d})$ electronic states of the as-prepared $\mathrm{CO}_{3} \mathrm{O}_{4}$ thorn-like nanostructures.

ties of the high index planes (511) and (440) is higher for 3D/ $\mathrm{Co}_{3} \mathrm{O}_{4}$ thorn-like nanostructures (Fig. 4a, curve b) than that for the nanowire morphology (Fig. $4 \mathrm{a}$, curve a), which reveals that the $3 \mathrm{D} / \mathrm{Co}_{3} \mathrm{O}_{4}$ thorn-like nanostructures were abundant in high index facets compared to the $3 \mathrm{D} / \mathrm{Co}_{3} \mathrm{O}_{4}$ nanowire morphology. The average size of the composed nanocrystal was about $33.8 \mathrm{~nm}$, calculated by the Scherrer's equation using the diffraction peak of the (311) plane of $\mathrm{Co}_{3} \mathrm{O}_{4}$ thorn-like nanostructures. The energy dispersive X-ray (EDX) analysis of the 
$3 \mathrm{D} / \mathrm{Co}_{3} \mathrm{O}_{4}$ thorn-like nanostructures is shown in Fig. $4 \mathrm{~b}$. The strong peaks for $\mathrm{Co}, \mathrm{O}$ and $\mathrm{C}$ are found in the spectrum, which corresponds to $\mathrm{Co}_{3} \mathrm{O}_{4}$ and $\mathrm{C}$ from the CFP (samples collected from the CFP surface), while the $\mathrm{Cu}$ peak comes from the $\mathrm{Cu}$ grid used for TEM measurements. The formation of $3 \mathrm{D} / \mathrm{Co}_{3} \mathrm{O}_{4}$ nanostructures was further confirmed by XPS measurements. Fig. $4 \mathrm{c}$ and $\mathrm{d}$ show the XPS spectra of Co $2 \mathrm{p}$ and $\mathrm{O} 1 \mathrm{~s}$ of the $\mathrm{Co}_{3} \mathrm{O}_{4}$ thorn-like nanostructures. As shown in Fig. 4c, the two strong peaks located at $780.1 \mathrm{eV}$ and $795.7 \mathrm{eV}$ were assigned to Co $2 \mathrm{p}_{2 / 3}$ and Co $2 \mathrm{p}_{1 / 2}$, respectively. ${ }^{56,57}$ After the deconvolution of the Co $2 \mathrm{p}_{2 / 3}$ branch, it can be seen that the peak of $\mathrm{Co}^{3+}$ is located at $780.1 \mathrm{eV}$ and that of $\mathrm{Co}^{2+}$ is located at $782.0 \mathrm{eV}$, which were in agreement with the binding energies of $\mathrm{Co}^{3+}$ and $\mathrm{Co}^{2+}$, respectively. ${ }^{58,59}$ The two peaks of the Co $2 \mathrm{p}_{1 / 2}$ branch located at 795.7 and $796.8 \mathrm{eV}$ have similar assignments to that of the Co $2 \mathrm{p}_{3 / 2}$ branch. Furthermore, the two peaks identified at $780.1 \mathrm{eV}$ and $795.7 \mathrm{eV}$ with a separation of $15.60 \mathrm{eV}$ correspond to the Co $2 \mathrm{p}_{3 / 2}$ and Co $2 \mathrm{p}_{1 / 2}$ orbitals of $\mathrm{Co}_{3} \mathrm{O}_{4}$ (Fig. 4c), respectively. ${ }^{60}$ The $\mathrm{O}$ 1s spectra as shown in Fig. 4d can be deconvoluted into two peaks at $530.0 \mathrm{eV}$ and $531.6 \mathrm{eV}$, and were attributed to the lattice oxygen in the $\mathrm{Co}_{3} \mathrm{O}_{4}$ and the oxygen in hydroxide ions, ${ }^{61}$ respectively, which further indicates the formation of $\mathrm{Co}_{3} \mathrm{O}_{4}$ nanostructures.

\section{Electrochemical oxidation of glucose in $3 \mathrm{D} / \mathrm{Co}_{3} \mathrm{O}_{4}$ thorn-like and nanowires on the CFP electrode}

Flexible CFP electrodes have increased interest for energy storage and sensing applications. ${ }^{18,45,47}$ Recently, we have synthesized 3D-Ni-Fe hierarchical nanostructures on the flexible CFP surface, which are applicable to the electrochemical determination of glucose. ${ }^{47}$ Here, we have tested the newly synthesized $3 \mathrm{D} / \mathrm{Co}_{3} \mathrm{O}_{4}$ thorn-like and nanowires for glucose determination. Fig. 5 a shows the $\mathrm{CV}$ profiles of the $3 \mathrm{D} / \mathrm{Co}_{3} \mathrm{O}_{4}$ nanostructures grown on the CFP electrode in $0.1 \mathrm{M} \mathrm{NaOH}$ as the electrolyte. Two pairs of redox peaks (I/II and III/IV) were observed for both $3 \mathrm{D} / \mathrm{Co}_{3} \mathrm{O}_{4}$ nanowires (green line) and thornlike (blue line) nanostructures (Fig. 5a), resulting from the reversible transition between $\mathrm{Co}_{3} \mathrm{O}_{4}$ and $\mathrm{CoOOH}(\mathrm{I} / \mathrm{II})$ and the transition between $\mathrm{CoOOH}$ and $\mathrm{CoO}_{2}$ (III/IV), which is consistent with a recent report. ${ }^{28}$ This observation was confirmed by the participation of $\mathrm{OH}^{-}$in the electrochemical redox reaction of $\mathrm{Co}_{3} \mathrm{O}_{4}$. The reactions can be written as follows;

$$
\begin{gathered}
\mathrm{Co}_{3} \mathrm{O}_{4}+\mathrm{OH}^{-}+\mathrm{H}_{2} \mathrm{O} \leftrightarrow 3 \mathrm{CoOOH}+\mathrm{e}^{-} \\
\mathrm{CoOOH}+\mathrm{OH}^{-} \leftrightarrow \mathrm{CoO}_{2}+\mathrm{H}_{2} \mathrm{O}+\mathrm{e}^{-}
\end{gathered}
$$

Noticeably, the unmodified CFP electrode doesn't show any electrochemical response (Fig. 5a, black line), which clearly confirmed the catalytic properties of $3 \mathrm{D} / \mathrm{Co}_{3} \mathrm{O}_{4}$ nanostructures.

The electrochemical oxidation of glucose in the $3 \mathrm{D} / \mathrm{Co}_{3} \mathrm{O}_{4}$ thorn-like nanostructures was first examined in a $0.1 \mathrm{M} \mathrm{NaOH}$ solution. Fig. 5b shows the CVs in the absence (curve i, blue line) and presence (curve ii, magenta line) of $0.05 \mathrm{mM}$ glucose, recorded on the $3 \mathrm{D} / \mathrm{Co}_{3} \mathrm{O}_{4}$ thorn-like nanostructures/CFP electrode in $0.1 \mathrm{M} \mathrm{NaOH}$ solution. The $3 \mathrm{D} / \mathrm{Co}_{3} \mathrm{O}_{4}$ thorn-like nanostructures started oxidizing glucose at $c a .+0.15 \mathrm{~V}$ and covered
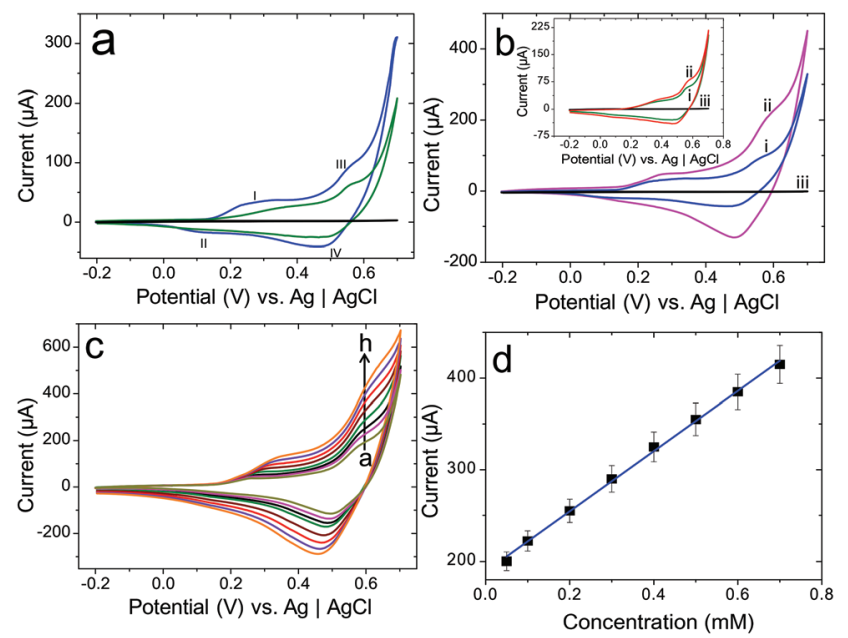

Fig. 5 (a) $\mathrm{CVs}$ of the $3 \mathrm{D} / \mathrm{Co}_{3} \mathrm{O}_{4}$ thorn-like (blue line), nanowire (green line) nanostructures and unmodified CFP (black line) electrodes in $0.1 \mathrm{M}$ $\mathrm{NaOH}$ solution. (b) $\mathrm{CVs}$ of the $3 \mathrm{D} / \mathrm{Co}_{3} \mathrm{O}_{4}$ thorn-like (blue line) and nanowire (green line, inset) nanostructure-modified CFP electrodes in the absence of glucose (i) and the presence (ii) of $0.05 \mathrm{mM}$ glucose in $0.1 \mathrm{M}$ $\mathrm{NaOH}$ solution. For control experiments, CVs are obtained for the unmodified CFP (black line) electrodes in $0.1 \mathrm{M} \mathrm{NaOH}$ solution containing $0.05 \mathrm{mM}$ glucose. (c) $\mathrm{CVs}$ of the $3 \mathrm{D} / \mathrm{Co}_{3} \mathrm{O}_{4}$ thorn-like nanostructure CFP electrode in $0.1 \mathrm{M} \mathrm{NaOH}$ solution at various concentrations of glucose; $0.05,0.1,0.2,0.3,0.4,0.5,0.6$, and $0.7 \mathrm{mM}$; (d) calibration plot of the corresponding $\left(3 \mathrm{D} / \mathrm{CO}_{3} \mathrm{O}_{4}\right.$ thorn-like nanostructure CFP electrode) glucose oxidation currents vs. the concentration of glucose $(n=3)$.

the potential region where species $\mathrm{CoOOH}$ and $\mathrm{CoO}_{2}$ were formed. No electrochemical signal was observed on the unmodified CFP electrode (curve iii, black line, as well as the inset). The result indicated that the catalytic properties of the as-prepared $3 \mathrm{D} / \mathrm{Co}_{3} \mathrm{O}_{4}$ thorn-like nanostructures towards glucose oxidation were associated with $\mathrm{CoOOH}$ and $\mathrm{CoO}_{2}$. Next, we have also studied the glucose oxidation on the $3 \mathrm{D} / \mathrm{Co}_{3} \mathrm{O}_{4}$ nanowiremodified CFP electrode (data shown in the inset of Fig. 5b) in the absence (curve i, green line) and presence (curve ii, red line) of $0.05 \mathrm{mM}$ glucose in $0.1 \mathrm{M} \mathrm{NaOH}$ solution.

Interestingly, the $3 \mathrm{D} / \mathrm{Co}_{3} \mathrm{O}_{4}$ thorn-like nanostructures showed significantly higher electrochemical oxidation of glucose than the $3 \mathrm{D} / \mathrm{Co}_{3} \mathrm{O}_{4}$ nanowire nanostructures. Additionally, as shown in Fig. 5c, a sharp increase in the current subsequent to glucose addition at peak III $(\mathrm{CoOOH} \rightarrow$ $\left.\mathrm{CoO}_{2}\right)$ was stronger than that noticed at peak $\mathrm{I}\left(\mathrm{Co}_{3} \mathrm{O}_{4} \rightarrow\right.$ $\mathrm{CoOOH}$ ) which unequivocally suggests that the electrochemical oxidation of glucose is primarily mediated by $\mathrm{CoOOH} / \mathrm{CoO}_{2}$ rather than $\mathrm{Co}_{3} \mathrm{O}_{4} / \mathrm{CoOOH}$. Therefore, the peak III potential was applied for subsequent amperometric detection (vide infra). Glucose upon oxidation produces gluconolactone through a 2-electron electrochemical reaction. ${ }^{62}$ The electrocatalytic oxidation of glucose by $\mathrm{Co}_{3} \mathrm{O}_{4}$ nanostructures is proposed to proceed through the following equation:

$$
\begin{gathered}
2 \mathrm{CoO}_{2}+\mathrm{C}_{6} \mathrm{H}_{12} \mathrm{O}_{6}(\text { glucose }) \rightarrow 2 \mathrm{CoOOH} \\
\left.+\mathrm{C}_{6} \mathrm{H}_{10} \mathrm{O}_{6} \text { (gluconolactone }\right)
\end{gathered}
$$


With the utilization of $\mathrm{CoO}_{2}$ and the generation of $\mathrm{CoOOH}$, the extent of reaction (6) would significantly favour the forward reaction $\left(\mathrm{CoOOH} \rightarrow \mathrm{CoO}_{2}\right)$, leading to an enhancement in the oxidation peak III upon the addition of glucose (Fig. 5b). Furthermore, the redox reaction of $\mathrm{CoOOH} / \mathrm{CoO}_{2}$ is accompanied by the repeated transfer of $\mathrm{OH}$ and $\mathrm{H}_{2} \mathrm{O}$, possible only in alkaline solution, between the interfaces of $\mathrm{CoO}_{2}$, $\mathrm{Co}_{3} \mathrm{O}_{4}$, and $\mathrm{CoOOH}$. Because of the formation of hydroxide and oxyhydroxide, $\mathrm{OH}^{-}$ions from the oxyhydroxide layer continue to permeate into the Co substrate. This could be supported by the improved conducting properties of the oxyhydroxide over the hydroxide, as well as the increased driving potential. Thus, the formation of a stable and sufficient number of $\mathrm{CoOOH} / \mathrm{CoO}_{2}$ redox couples is possible only when the CFP electrode was polarized at positive potentials in alkaline solution. Hence, the catalytically active $\mathrm{CoO}_{2}$ layer is activated only in a solution of high $\mathrm{pH}$ and therefore the sensitive detection of glucose is feasible only in alkaline solution in this system. The experimental observation was in good agreement with eqn (5)-(7). As shown in Fig. 5c, the introduction of glucose increases the oxidation current at peak III (at $+0.55 \mathrm{~V}$ ) in a concentration-dependent manner, while the current at peak I (at $+0.15 \mathrm{~V}$ ) remains nearly constant. A slight baseline drift was observed after multiple injections of glucose, which may be attributed to the variation of local $\mathrm{pH}$, faster glucose consumption with respect to diffusion, or the adsorption of intermediates on the active sites. The corresponding calibration curve (Fig. 5d) displays a linear correlation over a concentration range from $0.05 \mathrm{mM}$ to $0.70 \mathrm{mM}$ of glucose with a correlation coefficient of 0.9978 , indicating the excellent applicability of the flexible $3 \mathrm{D} / \mathrm{Co}_{3} \mathrm{O}_{4}$ thorn-like nanostructuremodified CFP electrode. Overall, the observed higher electrocatalytic activity of $3 \mathrm{D} / \mathrm{Co}_{3} \mathrm{O}_{4}$ thorn-like nanostructures can be explained as follows: (i) the thorn-like nanostructures offer a large electrochemically active surface area (the mass normalized electrochemically active surface area (ECSA) of $3 \mathrm{D} / \mathrm{Co}_{3} \mathrm{O}_{4}$ thorn-like nanostructures is $c a .14 .1 \mathrm{~m}^{2} \mathrm{~g}^{-1}$ and that of $3 \mathrm{D} /$ $\mathrm{Co}_{3} \mathrm{O}_{4}$ nanowires is $10.4 \mathrm{~m}^{2} \mathrm{~g}^{-1}$ ); (ii) the networked needle-like configuration and good electronic conductivity of $3 \mathrm{D} / \mathrm{Co}_{3} \mathrm{O}_{4}$ thorn-like nanostructures with abundant mesopores expanding from the surface to the bottom not only facilitate the transport of glucose molecules through the electrolyte/electrode interface, but also allow them to come into contact with more active sites, thus providing reliable electrical connections with the glucose molecules; and (iii) their compatibility, i.e. $3 \mathrm{D} /$ $\mathrm{Co}_{3} \mathrm{O}_{4}$ thorn-like nanostructures directly grown on the flexible current collector (CFP), enables the rapid integration to any device configuration.

\section{Amperometric detection of glucose in $3 \mathrm{D} / \mathrm{Co}_{3} \mathrm{O}_{4}$ thorn-like nanostructures on the CFP electrode}

Considering that the $i_{\text {pa }}$ at peak $\mathrm{O}_{\mathrm{III}}(+0.55 \mathrm{~V})$ increased significantly with the increase of glucose concentration from $\mathrm{CV}$ measurements, a potential of $+0.55 \mathrm{~V}$ was applied for the nonenzymatic chronoamperometric detection of glucose in $3 \mathrm{D} /$ $\mathrm{Co}_{3} \mathrm{O}_{4}$ nanostructure-modified CFP electrodes (curves $\mathrm{i}$ and $\mathrm{ii}$ in Fig. 6a are for thorn-like and nanowires, respectively) in the stirring $0.1 \mathrm{M} \mathrm{NaOH}$ solution. The typical $i-t$ curve on successive injection of glucose reached $97 \%$ of steady-state current in less than $2 \mathrm{~s}$, which is similar to what was previously reported for other non-enzymatic glucose sensors. ${ }^{63-65}$ The corresponding calibration curves were plotted (Fig. 6b) with correlation coefficient values of 0.999 (thorn-like nanostructures on the CFP electrode) and 0.998 (nanowires on the CFP electrode).

The sensitivity of both $3 \mathrm{D} / \mathrm{Co}_{3} \mathrm{O}_{4}$ nanowire and thorn-like nanostructure-modified CFP electrodes was calculated from Fig. $6 \mathrm{~b}$, and the $3 \mathrm{D} / \mathrm{Co}_{3} \mathrm{O}_{4}$ thorn-like nanostructure-modified CFP shows a higher sensitivity $\left(0.18 \mu \mathrm{A} \mu \mathrm{M}^{-1}\right.$ glucose $)$ than the $3 \mathrm{D} / \mathrm{Co}_{3} \mathrm{O}_{4}$ nanowire $\mathrm{CFP}$ electrode $\left(0.09 \mu \mathrm{A} \mu \mathrm{M}^{-1}\right.$ glucose). Furthermore, a wide range response of glucose was tested from 1 to $1000 \mu \mathrm{M}$ (Fig. 6c), and the limit of detection calculated for both $3 \mathrm{D} / \mathrm{Co}_{3} \mathrm{O}_{4}$ thorn-like nanostructure- and $3 \mathrm{D} / \mathrm{Co}_{3} \mathrm{O}_{4}$ nanowire-modified CFP electrodes from the standard deviation of the baseline current ${ }^{66}$ was found to be $0.046 \mu \mathrm{M}$ and $0.102 \mu \mathrm{M}$, respectively ( $\mathrm{S} / \mathrm{N}=3)$. We summarized the enzymeless glucose detection performance with different $\mathrm{Co}_{3} \mathrm{O}_{4}$-based nanostructured electrodes reported so far in Table S1. $\dagger$ The $3-\mathrm{D} / \mathrm{Co}_{3} \mathrm{O}_{4}$ thorn-like nanostructure electrode is found to exhibit sensitive nanomolar glucose detection (ref. 1-9 from the ESI $\dagger$ ). We further analyzed the amperometric responses of $1 \mu \mathrm{M}$ glucose (steps a, d, g, j, m, o and p), $100 \mu \mathrm{M}$ of ascorbic acid (AA, step b), dopamine (DA, step c), uric acid (UA, step e), acetaminophen (AP, step f), cysteine (step h), fructose (step i),
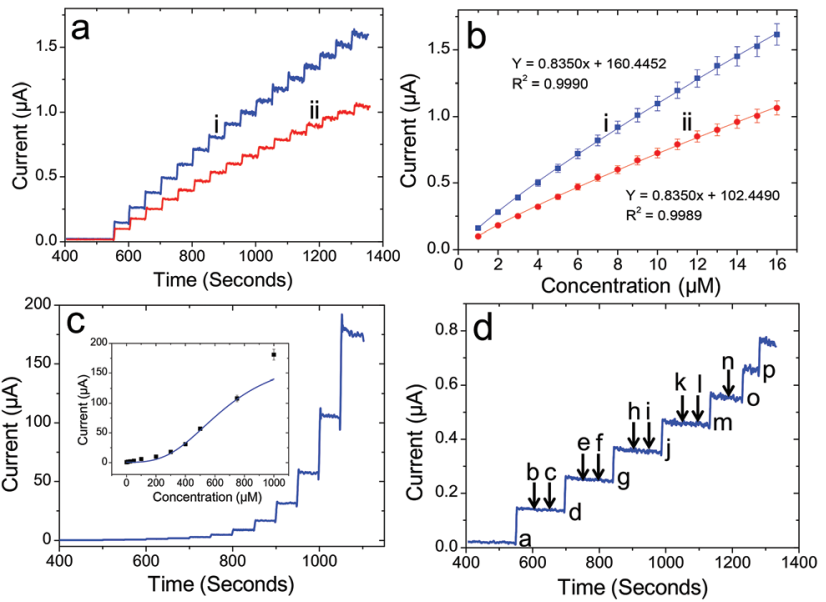

Fig. 6 (a) Amperometric $i-t$ curve response of the $3 \mathrm{D} / \mathrm{Co}_{3} \mathrm{O}_{4}$ thorn-like (i) and nanowire (ii) nanostructures on the CFP electrode at an applied potential of $+0.55 \mathrm{~V}$ in $0.1 \mathrm{M} \mathrm{NaOH}$ with the dropwise addition of $1 \mu \mathrm{M}$ glucose, and (b) the corresponding calibration plot of the obtained current response vs. glucose concentration. (c) Representative amperometric $i-t$ curve response of the $3 \mathrm{D} / \mathrm{CO}_{3} \mathrm{O}_{4}$ thorn-like nanostructures on the CFP electrode at $+0.55 \mathrm{~V}$ with the successive additions of glucose up to $1000 \mu \mathrm{M}$ in $0.1 \mathrm{M} \mathrm{NaOH}$ and the corresponding calibration plot of the obtained current response vs. glucose concentration. (d) Amperometric response of $3 \mathrm{D} / \mathrm{Co}_{3} \mathrm{O}_{4}$ thorn-like nanostructures on the CFP electrode towards the addition of $1 \mu \mathrm{M}$ glucose (steps $a, d, g, j, m, o$ and p) and interfering compounds of $100 \mu \mathrm{M} \mathrm{AA}(\mathrm{b}), \mathrm{DA}$ (c), UA (e), AP (f), cysteine (step h), fructose (step i), galactose (step k), lactose (step l), and serotonin (step $\mathrm{n}$ ) in constantly stirred $0.1 \mathrm{M} \mathrm{NaOH}$ solution. 
galactose (step k), lactose (step 1), and serotonin (step n), in $0.1 \mathrm{M} \mathrm{NaOH}$ solution, as shown in Fig. 6d. Notably, $3 \mathrm{D} / \mathrm{Co}_{3} \mathrm{O}_{4}$ thorn-like nanostructures provide remarkable responses only for glucose oxidation, and there is no amperometric current response for interfering species agreeing well with the Cobased electrodes. ${ }^{64,65,67,68}$

\section{Reproducibility and stability of the glucose sensor}

The reproducibility of the proposed sensor based on $3 \mathrm{D} / \mathrm{Co}_{3} \mathrm{O}_{4}$ thorn-like nanostructures was examined by measuring the catalytic current response of the electrochemical oxidation of glucose on three independent $3 \mathrm{D} / \mathrm{Co}_{3} \mathrm{O}_{4}$ thorn-like nanostructure CFP electrodes under the same conditions. The relative standard deviation (RSD) of the current response was only $2.87 \%$, indicating a good reproducibility. Furthermore, repeated measurements on the same CFP sensor showed a RSD of about $1.4-2.7 \%$. The long-term stability of the sensor is a critical factor in practical application; it was assessed by considering the amperometric response in $0.1 \mathrm{mM}$ glucose solution. The current response decreased less than $3 \%$ from its initial response current after 7 days of storage at $23{ }^{\circ} \mathrm{C}$.

\section{Validation of the proposed glucose sensor with real samples}

The $3 \mathrm{D} / \mathrm{Co}_{3} \mathrm{O}_{4}$ thorn-like nanostructure CFP electrode was tested with six different human blood serum samples (Muthu clinic and X-rays, Dindigul district) to validate the results under real-world conditions. $0.50 \mathrm{ml}$ of each of the blood serum samples were mixed with $9.5 \mathrm{~mL}$ of $0.1 \mathrm{M} \mathrm{NaOH}$ and used for the experiments. The experimental results are summarized in Table $\mathrm{S} 2 \dagger$ and compared with a standard hospital blood glucose determination method by using a commercial glucose sensor. The results show close agreement between these two sensor analyses, with a recovery of $\geq 95 \%$. These results confirmed that the proposed sensor could be applied to a sensing system for clinical applications.

\section{Conclusions}

In this work, a flexible CFP substrate was used as a support for the synthesis of $3 \mathrm{D} / \mathrm{Co}_{3} \mathrm{O}_{4}$ thorn-like and nanowire nanostructures by a one-step hydrothermal method. The $3 \mathrm{D} / \mathrm{Co}_{3} \mathrm{O}_{4}$ thorn-like and nanowire nanostructures were used for electrochemical non-enzymatic glucose sensing. The $3 \mathrm{D} / \mathrm{Co}_{3} \mathrm{O}_{4}$ thornlike nanostructures exhibit a higher catalytic activity towards the electrochemical oxidation of glucose compared to the $3 \mathrm{D} /$ $\mathrm{Co}_{3} \mathrm{O}_{4}$ nanowires. The $3 \mathrm{D} / \mathrm{Co}_{3} \mathrm{O}_{4}$ thorn-like nanostructures showed a higher sensitivity $\left(0.18 \mu \mathrm{A} \mu \mathrm{M}^{-1}\right.$ glucose $)$ than $3 \mathrm{D} /$ $\mathrm{Co}_{3} \mathrm{O}_{4}$ nanowires with a linear response of glucose concentration in the wide range of 1 to $1000 \mu \mathrm{M}$ and a LOD of $0.046 \mu \mathrm{M}(\mathrm{S} / \mathrm{N}=3)$. The $3 \mathrm{D} / \mathrm{Co}_{3} \mathrm{O}_{4}$ thorn-like nanostructures showed a stable, selective and reproducible electrochemical response towards the detection of glucose. In conclusion, the $3 \mathrm{D} / \mathrm{Co}_{3} \mathrm{O}_{4}$ thorn-like nanostructures show potential for the development of a non-enzymatic glucose sensor.

\section{Conflicts of interest}

There are no conflicts to declare.

\section{Acknowledgements}

Dr Palanisamy Kannan thanks the NanOtechnology Biomaterials and aLternative Energy Source for the ERA Integration [FP7-REGPOT-CT-2011-285949-NOBLESSE] project for financial support. The authors thank Dr Palaniappan Subramanian, Research Fellow, EWHA Womans University, Seoul, South Korea, for his fruitful discussions.

\section{References}

1 J. Wang, Chem. Rev., 2007, 108, 814-825.

2 C. Chen, Q. Xie, D. Yang, H. Xiao, Y. Fu, Y. Tan and S. Yao, RSC Adv., 2013, 3, 4473-4491.

3 K. Tian, M. Prestgard and A. Tiwari, Mater. Sci. Eng., C, 2014, 41, 100-118.

4 X. Cao, N. Wang, S. Jia and Y. Shao, Anal. Chem., 2013, 85, 5040-5046.

5 J. Xie, H. Cao, H. Jiang, Y. Chen, W. Shi, H. Zheng and Y. Huang, Anal. Chim. Acta, 2013, 796, 92-100.

6 X. Bo, J. C. Ndamanisha, J. Bai and L. Guo, Talanta, 2010, 82, 85-91.

7 M. Li, X. Bo, Y. Zhang, C. Han and L. Guo, Biosens. Bioelectron., 2014, 56, 223-230.

8 P. Wan, S. Yin, L. Liu, Y. Li, Y. Liu, X. Wang, W. Leow, B. Ma and X. Chen, Small, 2014, 10, 647-652.

9 Y. Meng, W. Song, H. Huang, Z. Ren, S.-Y. Chen and S. L. Suib, J. Am. Chem. Soc., 2014, 136, 11452-11464.

10 G. Zhang, B. Y. Xia, X. Wang and X. W. Lou, Adv. Mater., 2014, 26, 2408-2412.

11 W. van der Stam, Q. A. Akkerman, X. Ke, M. A. van Huis, S. Bals and C. de Mello Donega, Chem. Mater., 2014, 27, 283-291.

12 Z. Wang, J. Xue, D. Han and F. Gu, ACS Appl. Mater. Interfaces, 2014, 7, 308-317.

13 K. M. Haynes, C. M. Perry, M. Rivas, T. D. Golden, A. Bazan, M. Quintana, V. N. Nesterov, S. A. Berhe, J. Rodríguez, W. Estrada and W. J. Youngblood, ACS Appl. Mater. Interfaces, 2014, 7, 830-837.

14 H. Zhang, T. Ling and X.-W. Du, Chem. Mater., 2014, 27, 352-357.

15 P. Padwal, R. Bandyopadhyaya and S. Mehra, Langmuir, 2014, 30, 15266-15276.

16 Z. Cai, L. Xu, M. Yan, C. Han, L. He, K. M. Hercule, C. Niu, Z. Yuan, W. Xu, L. Qu, K. Zhao and L. Mai, Nano Lett., 2014, 15, 738-744.

17 A.-M. Cao, J.-S. Hu, H.-P. Liang, W.-G. Song, L.-J. Wan, X.-L. He, X.-G. Gao and S.-H. Xia, J. Phys. Chem. B, 2006, 110, 15858-15863. 
18 R. B. Rakhi, W. Chen, D. Cha and H. N. Alshareef, Nano Lett., 2012, 12, 2559-2567.

19 V. R. Shinde, S. B. Mahadik, T. P. Gujar and C. D. Lokhande, Appl. Surf. Sci., 2006, 252, 7487-7492.

20 I. G. Casella, J. Electroanal. Chem., 2002, 520, 119-125.

21 I. G. Casella and M. Gatta, J. Electroanal. Chem., 2002, 534, 31-38.

22 V. Srinivasan and J. W. Weidner, J. Power Sources, 2002, 108, 15-20.

23 N. Du, H. Zhang, B. D. Chen, J. B. Wu, X. Y. Ma, Z. H. Liu, Y. Q. Zhang, D. R. Yang, X. H. Huang and J. P. Tu, Adv. Mater., 2007, 19, 4505-4509.

24 H. Kim, D. Won Park, H. Chul Woo and J. Shik Chung, Appl. Catal., B, 1998, 19, 233-243.

25 T. Yoshino and N. Baba, Sol. Energy Mater. Sol. Cells, 1995, 39, 391-397.

26 L. Xu, Q. Jiang, Z. Xiao, X. Li, J. Huo, S. Wang and L. Dai, Angew. Chem., Int. Ed., 2016, 55, 5277-5281.

27 X.-C. Dong, H. Xu, X.-W. Wang, Y.-X. Huang, M. B. ChanPark, H. Zhang, L.-H. Wang, W. Huang and P. Chen, ACS Nano, 2012, 6, 3206-3213.

28 Y. Ding, Y. Wang, L. Su, M. Bellagamba, H. Zhang and Y. Lei, Biosens. Bioelectron., 2010, 26, 542-548.

29 L. Kong, Z. Ren, N. Zheng, S. Du, J. Wu, J. Tang and H. Fu, Nano Res., 2015, 8, 469-480.

30 Z. Zhu, X. Li, Y. Zeng, W. Sun, W. Zhu and X. Huang, J. Phys. Chem. C, 2011, 115, 12547-12553.

31 S. Elhag, Z. H. Ibupoto, X. Liu, O. Nur and M. Willander, Sens. Actuators, B, 2014, 203, 543-549.

32 S. Elhag, Z. Ibupoto, O. Nour and M. Willander, Materials, 2014, 8, 149-161.

33 L. Kong, Z. Ren, S. Du, J. Wu and H. Fu, Chem. Commun., 2014, 50, 4921-4923.

34 Y. Yang, D. S. Kim, R. Scholz, M. Knez, S. M. Lee, U. Gösele and M. Zacharias, Chem. Mater., 2008, 20, 3487-3494.

35 W. Y. Li, L. N. Xu and J. Chen, Adv. Funct. Mater., 2005, 15, 851-857.

36 Y. Li, B. Tan and Y. Wu, Nano Lett., 2007, 8, 265-270.

37 Y. Li, B. Tan and Y. Wu, J. Am. Chem. Soc., 2006, 128, 14258-14259.

38 K. T. Nam, D.-W. Kim, P. J. Yoo, C.-Y. Chiang, N. Meethong, P. T. Hammond, Y.-M. Chiang and A. M. Belcher, Science, 2006, 312, 885-888.

39 F. Zhang, C. Yuan, X. Lu, L. Zhang, Q. Che and X. Zhang, J. Power Sources, 2012, 203, 250-256.

40 L. Yang, S. Cheng, Y. Ding, X. Zhu, Z. L. Wang and M. Liu, Nano Lett., 2011, 12, 321-325.

41 D. Ye, L. Luo, Y. Ding, B. Liu and X. Liu, Analyst, 2012, 137, 2840-2845.

42 G. Wang, D. Cao, C. Yin, Y. Gao, J. Yin and L. Cheng, Chem. Mater., 2009, 21, 5112-5118.
43 L. Li, M. Liu, S. He and W. Chen, Anal. Chem., 2014, 86, 7996-8002.

44 X. Ji, D.-Y. Liu, D. G. Prendiville, Y. Zhang, X. Liu and G. D. Stucky, Nano Today, 2012, 7, 10-20.

45 L. Yang, S. Cheng, Y. Ding, X. Zhu, Z. L. Wang and M. Liu, Nano Lett., 2012, 12, 321-325.

46 R. Mohammadzadeh Kakhki, Arabian J. Chem., 2014, DOI: 10.1016/j.arabjc.2014.11.058.

47 P. Kannan, T. Maiyalagan, E. Marsili, S. Ghosh, J. Niedziolka-Jonsson and M. Jonsson-Niedziolka, Nanoscale, 2016, 8, 843-855.

48 A. R. Roosen and W. C. Carter, Phys. A, 1998, 261, 232-247.

49 B. Gao, M. J. Rozin and A. R. Tao, Nanoscale, 2013, 5, 56775691.

50 M.-R. Gao, S.-R. Zhang, Y.-F. Xu, Y.-R. Zheng, J. Jiang and S.-H. Yu, Adv. Funct. Mater., 2014, 24, 916-924.

51 D. P. Singh, N. R. Neti, A. S. K. Sinha and O. N. Srivastava, J. Phys. Chem. C, 2007, 111, 1638-1645.

52 E. P. Randviir and C. E. Banks, Anal. Methods, 2013, 5, 1098-1115.

53 M. Ates, Prog. Org. Coat., 2011, 71, 1-10.

54 M. Aghazadeh, J. Appl. Electrochem., 2012, 42, 89-94.

55 Y. Li, K. Huang, S. Liu, Z. Yao and S. Zhuang, J. Solid State Electrochem., 2011, 15, 587-592.

56 G. Du, X. Liu, Y. Zong, T. S. A. Hor, A. Yu and Z. Liu, Nanoscale, 2013, 5, 4657-4661.

57 B. G. Choi, S.-J. Chang, Y. B. Lee, J. S. Bae, H. J. Kim and Y. S. Huh, Nanoscale, 2012, 4, 5924-5930.

58 L. Lv, Y. Su, X. Liu, H. Zheng and X. Wang, J. Alloys Compd., 2013, 553, 163-166.

59 J. Wu, Y. Xue, X. Yan, W. Yan, Q. Cheng and Y. Xie, Nano Res., 2012, 5, 521-530.

60 Z.-W. Fu, Y. Wang, Y. Zhang and Q.-Z. Qin, Solid State Ionics, 2004, 170, 105-109.

61 S. Xiong, J. S. Chen, X. W. Lou and H. C. Zeng, Adv. Funct. Mater., 2012, 22, 861-871.

62 S. Park, H. Boo and T. D. Chung, Anal. Chim. Acta, 2006, 556, 46-57.

63 K. K. Lee, P. Y. Loh, C. H. Sow and W. S. Chin, Electrochem. Commun., 2012, 20, 128-132.

64 M. Li, C. Han, Y. Zhang, X. Bo and L. Guo, Anal. Chim. Acta, 2015, 861, 25-35.

65 L. Han, D.-P. Yang and A. Liu, Biosens. Bioelectron., 2015, 63, 145-152.

66 H. R. Zare, F. Memarzadeh, M. M. Ardakani, M. Namazian and S. M. Golabi, Electrochim. Acta, 2005, 50, 34953502 .

67 Z. H. Ibupoto, S. Elhag, M. S. AlSalhi, O. Nur and M. Willander, Electroanalysis, 2014, 26, 1773-1781.

68 C. Guo, X. Zhang, H. Huo, C. Xu and X. Han, Analyst, 2013, 138, 6727-6731. 